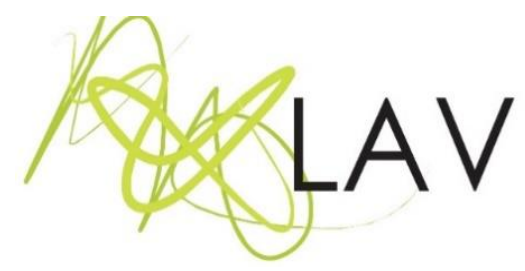

\title{
Formar professores, um gesto de resistência
}

Educating teachers, an act of resistance

Daniel Bruno Momoli ${ }^{i}$

Universidade Alto Vale do Rio do Peixe e Faculdade SENAC

\section{Resumo}

O gesto de resistência descrito neste texto é constituído pelo cruzamento de duas linhas de força que se entrelaçam: a primeira, consiste na confissão da pobreza de experiência de um professor formador de professores; e a segunda é uma problematização sobre a formação de professores como lugar de resistência capaz de permitir a criação de formas outras de estar no mundo. Tal tessitura se abre para uma segunda problematização em relação ao que é vivido no Brasil desde o ano de 2016, e do quanto esse gesto de formar professores é uma atividade que, nesse momento, desafia a sociedade, na medida em que pode ser um lugar de instituição de novas formas de vida. São coisas diferentes colocadas em relação a partir do pensamento de Michel Foucault para fazer conversar entre si de um modo que seja possível transformar as nossas relações com a atualidade.

Palavras-chave: formação docente, subjetividade, experiência, política, ética.

\section{Abstract}

The resistance action described in this text is constituted by the crossing of two force lines that intertwine: the first consists in the confession of a poor experience by a teacher who forms teachers; and the second is a problematization about the formation of teachers as a place of resistance capable of allowing the creation of other ways of being in the world. This opens up a second problematization in relation to what has been lived in Brazil since the year 2016 and how this gesture of teacher training is an activity that currently challenges society as it can be a place for instituting new forms of life. They are different things put into relation from the thought of Michel Foucault to make talking possible among themselves in a way that it is possible to transform our relations with the present time.

Keywords: teacher student, subjectivity, experience, politics, ethics.

Enviado em: 30/05/18 - Aprovado em: 09/11/18

\section{O que significa pensar a formação de professores após um massacre?}

Algumas perguntas, mais do que interrogações ao próprio pensamento, são marcas cingidas nos nossos corpos e histórias. Não se encontra uma resposta clara para elas. 0 que se produz são movimentos que nos colocam para além de nós mesmos. Há vários motivos que nos impulsionam a tal interrogação. Quanto a mim, me faço essa pergunta insistentemente diante de uma agenda de pesquisa, que insiste em apagar ou esconder atrás das palavras dos autores os motivos que me deram força - e que ainda me alimentam - a insistir na formação inicial de docentes. Talvez, em algum momento, eu encontre outras formas de fazer essa mesma pergunta. Talvez uma forma mais encarnada; no momento, 
eu só consigo pensar que, depois do massacre do dia 29 de abril de 2015, me tornei estranho a minha própria história.

Escrever sobre isso é um desafio, pois narrar uma experiência de crueldade é reviver a dor em cada palavra escrita. É ser tomado por um ódio indescritível pelo desrespeito ao qual se foi submetido. Meus olhos ardem e minha garganta queima como se eu tivesse que inalar ininterruptamente os gases e o vapor daquele dia em que fui destituído de toda minha autoridade, de todo o meu respeito e no qual minha experiência de docência ficou empobrecida diante de um espetáculo de horrores com mais de duas horas de duração.

Se, durante tantas vezes, relutei para não escrever, ou se chorei diante da palavra dita que eu precisava escrever sobre aquele dia, é por que me faltava a suficiente coragem de encarar a minha história e de encontrar alguma forma de dizer os motivos que me fazem enfrentar qualquer luta e qualquer embate que envolva a experiência democrática e que não permita mais nenhum retrocesso em nosso país.

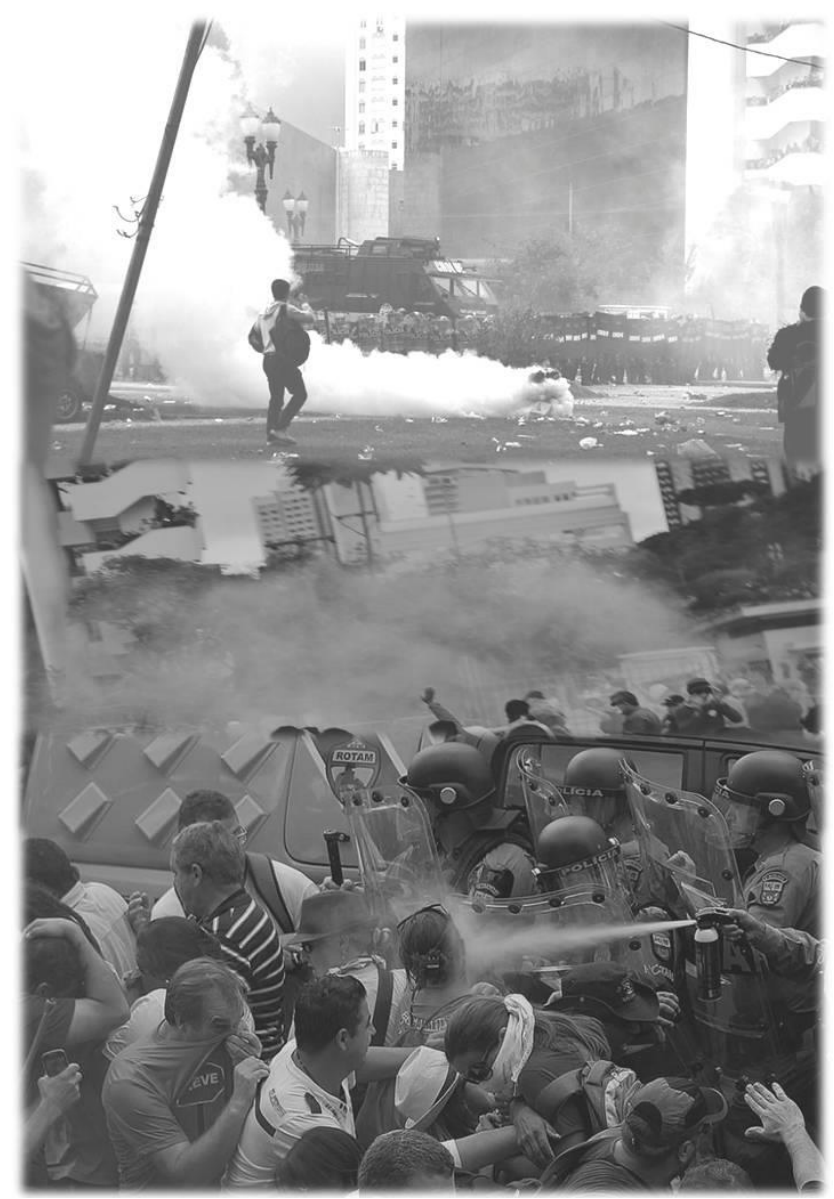

Figura 01. A destituição da experiência de um professor formador de professore Fonte: Arquivo do autor (2016-2017) ${ }^{1}$

\footnotetext{
${ }^{1}$ A imagem é uma montagem elaborada a partir de um arquivo formado com diferentes fontes datadas dos anos de 2015 e 2016 sobre "o massacre dos professores de Curitiba-PR". Tal narrativa visual é uma composição fez
} 
Para escrever sobre isso, eu precisava vencer o meu medo. E o meu medo é o SILÊNCIO! Pois o silêncio das noites trazia os sons de uma sinfonia dos horrores: do barulho das bombas, dos gritos e dos murmúrios de choro. Do coro de uma multidão que não se cansava de pedir socorro para resgatar as vítimas em plena praça pública, desacordadas, mas mantidas vivas com jatos de água espirrados por um monstruoso caminhão, blindado por um batalhão de choque.

A noite e o silêncio me fizeram lembrar por muitos dias a pior de todas as experiências que um professor pode ter. Não apenas pelo desrespeito, pela crueldade ou pela violência. Mas, por que fui atravessado por algo que me colocou ao avesso daquele que eu era. De professor a "Black bloc". Nossas casas se tornaram as barracas nas praças e prédios públicos.

As fileiras que diariamente percorríamos nas salas de aula foram trocadas pelas vielas formadas por barracas e estreitos corredores entre o acampamento e a trincheira armada por um batalhão de policiais. O sinal de troca das aulas foi substituído por intermináveis toques de segurança. Nossas cadeiras foram substituídas pelas árvores de uma praça pública que se tornaram banco, mesa, colchão e abrigo.

Os policiais estavam em todos os lugares, saiam de qualquer esquina, nos vigiavam nas fileiras dos banheiros, nas ruas, no mercado, em qualquer lugar. Estavam ali ao nosso lado ou no céu sobrevoando o acampamento em helicópteros. Não tínhamos nada a não ser uns aos outros. No início, éramos poucos e eles, muitos. Depois, nos tornamos muitos, milhares e eles eram poucos. Por fim, nos tornamos uma multidão. Eles chegavam com armas. Nós, com olhares desconfiados sobre o que poderia acontecer ali. Prontos para ir além dos nossos próprios limites, se preciso fosse.

Cada uma das pessoas que estava naquela praça guardava um resto de esperança, aquela que nem mesmo a gente acreditava que tinha. E mesmo em uma praça pública com milhares de pessoas, de inúmeras câmeras, das mais variadas formas de manifestação coletiva social, nada foi capaz de fazer parar aquele confronto. Um enfrentamento que começou com uma ofensiva para impedir que a votação de um projeto de lei fosse interrompida.

parte de um exercício de escrita que desenvolvi para o Projeto de Tese intitulado "Por uma possível dimensão estética na Licenciatura em Artes Visuais: tensões e problematizações" que foi desenvolvido na linha de pesquisa Arte, Linguagem e Currículo" do Programa de Pós-graduação em Educação da Universidade Federal do Rio Grande do Sul, sob supervisão da Profa. Dra. Luciana Gruppelli Loponte.

Revista Digital do LAV - Santa Maria - vol. 11, n. 3, p. 67 - 81 - set./dez. 2018 ISSN 1983 - 7348 http://dx.doi.org/10.5902/1983734832832839 
As bombas começaram a vir de todos os lados: dos prédios, do meio dos policiais, de grupos escondidos nos jardins internos da ALEP, dos helicópteros. Os policiais começavam a avançar em batalhão. Disparos, bombas, cassetetes. Para eles, foi um confronto de duas horas que envolveu 1.661 soldados da Policia Militar; 2.323 balas de borracha e 1413 bombas de efeito moral em um confronto de mais de duas horas, que deixou 200 pessoas feridas. Para a Justiça, não houve excessos ou crimes por parte do Estado, que apenas cumpriu o seu papel.

Mas, para Nós, foi o início de uma história que parece não ter fim, pois é como se as bombas estourassem de novo a cada dia 29 e diante das tiranias que sufocam as três décadas de caminhos e práticas democráticas percorridas neste e por este país (Adaptação de Notas de escrita; Diário de Pesquisa; agosto e setembro de 2016)².

Curitiba, 29 de abril de 2015. Na praça situada entre o Palácio das Araucárias - sede administrativa do Governo do estado do Paraná - e a Assembleia Legislativa do Paraná ALEP, uma multidão de mais de 30 mil pessoas, a maioria formada por professores estaduais, foi agredida por policiais. Após dois dias de acampamento, um ataque ofensivo continuou ininterruptamente por duas horas e a estimativa foi de que, a cada 24 segundos, um disparo - de bomba de efeito moral e balas de borracha - era feito contra professores. Desse enfrentamento, ficaram 200 feridos. O ataque foi denunciado no Ministério Público, que isentou o Estado de qualquer culpa, pois tal ação não incorreu contra nenhum direito. ${ }^{3}$ A história do dia 29 de abril de 2015 poderia ser uma história como a de tantas outras pessoas que escolhem uma causa e que se ocupam dela em diferentes frentes e movimento. Mas, esta é a minha história. ${ }^{4} \mathrm{~A}$ história de um professor formador de

\footnotetext{
${ }^{2}$ Este texto é uma adaptação de um conjunto de notas de escrita que foram elaboradas entre os anos de $2016 \mathrm{e}$ 2017 no Diário de Pesquisa que acompanhou o processo de construção do Projeto de Tese "Por uma possível dimensão estética na Licenciatura em Artes Visuais: tensões e problematizações" para mais informações vide nota 1.

${ }^{3}$ Nesse dia, milhares de professores do estado do Paraná protestavam contra um pacote de medidas tomado pelo governo daquele estado, que tinha como principal estratégia o saque de recursos financeiros reservados para as aposentadorias dos servidores. Para ser possível, a medida precisava da aprovação dos deputados estaduais. Porém, o parlamento estava cercado por uma manifestação com mais de 30 mil pessoas. Com forte aparato policial, que incluiu carros blindados, helicópteros e cães, os líderes dos poderes executivo e legislativo prepararam a sessão de votação. Transportados em um camburão, deputados favoráveis ao governo mandaram serrar a grade lateral da Assembleia Legislativa, desprezando a porta da frente, interditada pela manifestação. Este dia terminou com um grave confronto entre os policiais e professores.

${ }^{4} \mathrm{~A}$ opção estilística que faço nesta escrita é a de uma trama polifônica urdida entre o eu e o nós, pois me vejo na bifurcação desses dois lugares de fala. Por vezes, sou eu, o Daniel/estudante/professor/militante escrevendo e narrando as minhas histórias; por outras, somos nós, um coletivo de estudantes e pesquisadores que se reúnem quinzenalmente às terças-feiras no PPGEdu/UFRGS sob orientação da Professora Dra. Luciana Gruppelli Loponte para produzir formas de resistência/(re)existências que fazem pulsar a intensidade da arte, da docência e da formação na pesquisa em educação. Tal gesto é produzido também pelos movimentos criados em nosso grupo de pesquisa Arteversa - grupo de estudos e pesquisas em arte e docência. Para saber mais sobre o nosso trabalho consulte o site: https://www.ufrgs.br/arteversa/.
} 
professores; a história de um professor que se fez na e pela escola e que a toma pelo seu meio, para compreender a formação inicial de docentes. ${ }^{5}$

O tremor causado por essa que é uma das mais miseráveis formas de experiência quando se é um professor formador de professores é levada em consideração aqui para dar visibilidade ao visível. São as relações de poder e de saber que precisamos interrogar, não para explicar o que se passou, tampouco para dizer o que precisa ser feito, mas, para "diagnosticar as forças que constituem nossa atualidade" (ARTIÈRES, 2004, p. 16) e como nos movimentamos e somos produzidos por elas. Desse modo, este texto se divide em duas partes. Na primeira, apresento a formação de professores como um lugar de resistência e para tanto são apresentados os movimentos que fizeram da escrita um espaço de elaboração de si mesmo após a confissão da minha pobreza de experiência. Depois, apresento a intensidade de seguir pensando a formação docente a partir de um micropolítica da subjetividade. Tudo isso, talvez, faça parte de uma tentativa de habitar esse mundo, "um modo de relação que concerne à atualidade (...) uma maneira de pensar e de sentir, uma maneira também de agir e de se conduzir" (FOUCAULT, 2005, p. 341). Ou constitua ainda uma tentativa de "perceber no escuro" do presente essa luz que procura alcançar-nos (AGAMBEN, 2010, p. 64), que, dirigida para nós, distancia-se infinitamente.

\section{A formação de professores como um lugar de resistência e re-existência}

Investir em uma escrita sobre educação e formação docente, depois de ser atravessado por essa radical experiência, é um exercício de labor, de um trabalho sobre si mesmo, instigado por uma interrogação: o que é possível ser dito após um massacre ou o que sobra após uma das mais miseráveis formas de experiência quando se é um professor formador de professores? (Adaptação de Notas de escrita; Diário de Pesquisa; 12 de setembro de 2016). Ao fazer-me - diariamente - essa pergunta, tenho tentado tomar certo distanciamento desses fatos "e dos implacáveis regimes de verdade que tanto o fustigam" (AQUINO, 2014, p. 98), na tentativa de traçar outros caminhos para a formação de docentes, um gesto, talvez ético ou político, que é alimentado pelas perguntas formuladas por Foucault (2005) diante das interrogações de Immanuel Kant em relação à modernidade - Was ist Aufklärung - "o que se passa hoje? O que se passa agora?".

Ao deter-se na pergunta kantiana, Michel Foucault aponta para questões em torno de um conjunto de situações de seu tempo e mostra que é possível "interrogar o presente para nele tentar decifrar os sinais que anunciam um acontecimento iminente". O desafio lançado

\footnotetext{
${ }^{5}$ Neste texto, vou deter-me a pensar a formação docente de maneira ampla, mas, meus estudos estão implicados diretamente com o tema da Licenciatura em Artes Visuais.
}

Revista Digital do LAV - Santa Maria - vol. 11, n. 3, p. $67-81$ - set./dez. 2018 ISSN 1983 - 7348 http://dx.doi.org/10.5902/1983734832832839 
a partir das perguntas foucaultianas indica uma possibilidade de encarar a modernidade mais como atitude do que um período histórico. Ao fazer isso, Foucault (2005, p. 341) explica que quando trata de atitude quer dizer "um modo de relação que concerne à atualidade (...) uma maneira de pensar e de sentir, uma maneira também de agir e de se conduzir" e que tudo, ao mesmo tempo, marca uma pertinência e apresenta-se como uma tarefa. Trata-se de uma ruptura, um desvio em relação à maneira que se produziu um modo de pensar a partir do século XVIII.

Talvez as perguntas - que principiam este texto - sejam menores que aquelas formuladas pelo filósofo. No entanto, elas permitem-me entrar discretamente em um campo denso, o da formação de professores, e ao mesmo tempo problematizar "a relação com o presente, o modo de ser histórico e a constituição de si próprio" (FOUCAULT, 2005, p. 345). Ao reescrever as interrogações de Foucault, tento experimentar por meio de um fazer investigativo a criação de um campo possível de resistência que se coloca como uma possibilidade de entendimento do presente e também um modo de agir e de inventar formas de (re)existências ${ }^{6}$, seja na escola ou na vida.

Não há uma ordem dos saberes que dê conta de organizar os pensamentos para descrever às pessoas o que se passou. É uma experiência radicalmente desmoralizada e da qual a linguagem não dá conta, pois se passa no fundo sem fundo do pensamento. "Quando a experiência nos é subtraída, hipócrita ou sorrateiramente [é uma prova de honradez] confessar nossa pobreza" (BENJAMIN, 1993, p. 115), para que ela faça-nos olhar para frente e começar de novo, "sem olhar nem para direita nem para a esquerda", sem a intenção de descrever, mas pensar a transformação. "Na passividade do desastre, é a parte inumana do homem que vem à tona, como dispersão, defecção, abdicação anônima (...), o desastre interrompe a ordem do mundo" (PELBART, 2011, p. 2).

A dor me deu forças que nem eu imaginava que tinha. [É uma dor] Que me faz pensar todas as noites que eu deito; que a luta não para nenhum dia, nenhum momento; ela não dá trégua, por que a vida que eu escolhi está do lado oposto de uma sociedade que explora, massacra, oprime, agride invisibiliza e exclui todos nós que somos chamados de outros. (Nota de Escrita: "esboçar uma escrita - criar", 12 de setembro de 2016).

Essas narrativas, que algumas coisas contam, "contêm no seu centro, algo que é intestemunhável, que destitui a [nossa] autoridade" (AGAMBEN, 2008, p. 43) e que nos

\footnotetext{
${ }^{6}$ Esta expressão - (re)existência - é um termo que ganhou muita força durante as manifestações e protestos realizados no Brasil durante o ano de 2016 como forma de oposição ao nefasto conjunto de estratégias políticas que colocam em risco a construção democrática brasileira. Ao investir no uso desse termo, tento trazer a essa escrita as vozes das ruas que dizem não a tudo isso que estamos vivendo na atualidade.
} 
rouba a palavra, deixando-nos mais pobres. Se o que nos resta é o silêncio, pois nenhuma palavra é suficiente para dizer tudo aquilo que se presenciou, talvez possa a escrita constituir-se como uma "arena política" (PEREIRA, 2016, p. 213), um lugar de travar lutas, em que "palavra se encarrega não de preencher ou atravessar, mas de sustentar e acolher, colocando o próprio pensamento em estado de exterioridade, de estrangeiridade, de distância, de abismo" (PELBART, 2011, p. 3). Ao enfrentar o medo e usar a palavra, fui confessando a minha pobreza e, simultaneamente, inscrevendo pela escrita um registro para não permitir que essa história seja apagada pelas sombras do agora. Uma tentativa de deixar um testemunho sobre a atualidade nos mais diferentes documentos, para que, um dia, se possa perquirir a história de outro presente a partir da projeção das sombras de um passado que é o nosso tempo de agora.

Se, na segunda metade do século $X X$, a exigência das pesquisas e das investigações no campo da educação era que Auschwitz não se repetisse; de tal modo para nós, hoje, nas primeiras décadas do século XXI, "ela precede quaisquer outras que creio não ser possível nem necessário julgá-Io" (ADORNO, 1995, p. 1), pois o fantasma do passado esconde-se diante das portas que trazem as novas ameaças ao nosso presente (BENJAMIN, 1993). Se justificar a história de Auschwitz seria abominável diante de todo o horror ali envolvido, talvez tenhamos falhado por não ter esgotado a barbárie que foi aquele terrível episódio da história mundial. "A pouca consciência existente em relação a essa exigência e as questões que ela levanta provam que a monstruosidade não calou fundo nas pessoas".

A história do confronto entre os Policias Militares do Paraná e os Professores não contém a mínima fração do que foi Auschwitz. Não se pode fazer uma aproximação entre esses fatos, mas se pode pensar em um e no outro e na destituição da experiência de quem deles retornou. Há algo que ficou e que se move modificando nossos modos de ser (Adaptação de Notas de escrita; Diário de Pesquisa; novembro de 2016). Entrar em uma sala de aula para trabalhar com crianças e adolescentes em uma escola ou com professores em formação na universidade não é a mesma coisa depois daqueles dias.

Em um pequeno diálogo entre Theodor Adorno e Walter Benjamin, no texto "educação após Auschwitz", há uma preocupação de Benjamin: a quantidade de algozes em Paris que pudessem dar continuidade aos assassinatos ordenados pelos nazistas. O que o filósofo percebia é que "ao contrário dos assassinos de gabinete e dos ideólogos, as pessoas que executam as tarefas agem em contradição com seus próprios interesses imediatos, são assassinas de si mesmas na medida que assassinam os outros" (ADORNO, 1995, p.8). Se fomos e continuamos sendo incapazes de fazer parar as mais terríveis formas de crueldade

Revista Digital do LAV - Santa Maria - vol. 11, n. 3, p. 67 - 81 - set./dez. 2018 ISSN 1983 - 7348 http://dx.doi.org/10.5902/1983734832832839 
com a humanidade sob justificativa do capital, das religiões ou de um poder soberano sobre os outros, talvez seja preciso interrogar sobre os elementos desesperadores de nossa própria natureza; se não quisermos cair nas presas de uma retórica idealista ou salvacionista, é preciso correr o risco e interrogar-se sobre o que temos feito.

No risco de fazer essa interrogação, procuro colocar em suspensão a formação de docentes após o dia 29 de abril de 2015. Sem a intencionalidade de depositar na escrita certa verdade por ter participado daquele ato de repressão ou mesmo de encher-me de profunda descrença. Ao investir nessas formulações em torno da pesquisa, da escrita e da palavra, o que proponho é fazer uma suspensão do "consolador estado de certezas para, no lugar delas, construir e pensar fatos, coisas, dados, situações inquietantes de nosso tempo" (FISCHER, 2002, p. 61), penso, assim, numa suspensão feita a partir de conceitos que nos propiciem complexificar o real e tornar visível o visível. Trabalhar com essa condição não significa que temos como interesse buscar as origens, os começos, mas, as recorrências e as descontinuidades que nos atravessam. Uma atividade que requer "o desvio de certa naturalidade" do nosso olhar em relação ao que nos espreita, sobre um ou outro fato, uma ou outra prática.

Esse desvio muito mais que nos levar à verdade das coisas, permite experimentar o próprio pensamento a partir dos modos de fazer e propor uma investigação, visto que se aceitamos a aventura para além do que nos é conhecido e tranquilizador, há que se reinventar novos conceitos, problematizar os já vivenciados e correr riscos: "o que pode significar também que estejamos assumindo uma atitude relativa não só na nossa prática profissional, mas, antes, a uma genuína prática de vida" (FISCHER, 2002, p. 70). Assim, o gesto do pesquisador passa a ser uma forma de exercitar um modo de vida, estudar e viver o próprio presente.

$\mathrm{Na}$ tentativa de experimentar o próprio pensamento e de compor uma escrita sobre a formação de docentes, após a forma miserável de experiência que me destituiu da minha própria história, assumo a tarefa de questionar o mais evidente, o óbvio e investir na formulação de perguntas que, mais que interrogar um campo teórico, façam interrogações ao nosso próprio tempo para pensar e problematizar um presente marcado pela incerteza, não considerando, nesse caso, a incerteza como potência do pensamento, mas a incerteza advinda de um campo que é os das políticas públicas e do Estado e que diz respeito ao momento que hoje vivemos no Brasil. A cassação do mandato de uma Presidenta legitimamente eleita por meio do voto popular; da exoneração dos membros do Conselho 
Nacional de Educação - $\mathrm{CNE}^{7}$; de uma reforma educacional imposta por meio de Medida Provisória; de um Projeto de Emenda Constitucional - $\mathrm{PEC}^{8}$ que congelou por vinte anos os investimentos em áreas prioritárias como educação, saúde e segurança ${ }^{9}$.

Esses fatos dizem respeito a um conjunto de situações ocorridas no Brasil durante o ano de 2016. De um processo de impeachment sofrido por Dilma Rousseff em um transcurso de tempo que se desdobrou em nove meses e que levou o seu Vice a assumir a Presidência da República e dar início a uma política de austeridade alinhada fortemente a um pensamento neoliberalista conservador, que atinge prioritariamente as áreas sociais e programas de governo que priorizavam o alargamento mínimo de direitos sociais entendidos como fundamentais na construção democrática feita pelo país entre 1985 e 2016, no período pós-ditadura militar. "Tudo isso se repete e não está amarrado. No fundo, tudo isso não para de dizer a mesma coisa e, contudo, talvez não diga nada; tudo isso se entrecruza numa embrulhada pouco decifrável, que não se organiza muito" (FOUCAULT, 2010c, p. 5). Talvez possamos encontrar pontos de apoio caracterizando esse período por suas descontinuidades e na dispersão de alguns acontecimentos que vão dando visibilidades a certas fragilidades sobre como chegamos até este atual momento. Nessa embrulhada, há um conjunto de colisões que ressoam sobre o campo da educação, em alguns momentos, em pequenas cesuras, em outros, em cortes de grande profundidade, as "velhas relações não se esgotaram ou não morreram e as novas ainda não puderam nascer" (FRIGOTTO, 1996, p. 76). ${ }^{10}$

\section{A intensidade de seguir pensando a formação docente}

\footnotetext{
${ }^{7}$ A revogação da nomeação de 12 membros do Conselho Nacional de Educação CNE, que haviam sido nomeados pela Presidente Dilma Rousseff, foi feita pelo Presidente Michel Temer, por meio de um Decreto assinado em 28 de junho de 2016. Mais informações: <http://agenciabrasil.ebc.com.br/educacao/noticia/2016-06/temerrevoga-nomeacao-de-12-conselheiros-de-educacao-feita-por-dilma>.

${ }^{8}$ A PEC é uma sigla que se refere a um Projeto de Emenda Constitucional, um dispositivo criado para propor uma adição ou modificação ao texto de uma Lei Maior - no Brasil é a Constituição Federal de 1988 -, sem que sejam feridos os seus princípios básicos.

${ }^{9}$ Outras referências para compreender esse panorama são os textos: "O golpe - Da queda de Eduardo Cunha à denúncia contra Lula" - escrito por Céli Pinto - Disponível em: <http://www.bohngass.com.br/bohngass/noticias/item?item_id=2720571>; E o texto de Inácio Vieira "Michel Temer diz que impeachment aconteceu porque Dilma rejeitou ponte para o futuro". Disponível em: <https://theintercept.com/2016/09/22/micheltemerdizqueimpeachmentaconteceuporquedilmarejeitoupontepar aofuturo/>.

10 Faço menção ao autor devido ao tema por ele abordado no texto os novos desafios para "formação e a profissionalização do educador" na seara da promulgação da LDB 9.394/1996 e de uma década marcada pela queda do muro de Berlim, do colapso do socialismo (realmente existente), do fim de um determinado período histórico: "o fim das classes sociais, particularmente do proletariado e o surgimento do cognitariado, o fim das grandes utopias, o fim das ideologias, o fim da razão" (FRIGOTTO, 1996, p. 75-76). Para o autor, o tema da formação e da qualificação não poderia ser tratado sem estar referido a uma trama de relações sociais e embates que estavam travados no plano estrutural e conjuntural da sociedade, que, naquele momento, estava sob uma avassaladora ideologia neoliberal para ajustar a educação aos desafios daquele tempo. Talvez pareça distante o que escreve o autor em relação aos referenciais teóricos deste projeto, mas, há algo nele que convoca o meu olhar no momento em que referido autor aponta "a subordinação do educativo e dos processos de conhecimento à lógica da produção e do mercado [que] resulta em concepções e práticas dualistas, fragmentárias e profundamente etnocêntricas" (FRIGOTTO, 1996, p. 90).
}

Revista Digital do LAV - Santa Maria - vol. 11, n. 3, p. $67-81$ - set./dez. 2018 ISSN 1983 - 7348 http://dx.doi.org/10.5902/1983734832832839 
O investimento sempre necessário no campo da formação inicial de docentes é uma forma de experimentar a criação com a palavra na problematização das questões do nosso tempo, uma planície que não se caracteriza como "monótona e indefinidamente prolongada" (FOUCAULT, 2010b, p. 146), nem tão pouco faz aparecer um elemento inerte, liso e neutro sobre o objeto de estudo. Antes, o que faz é fazer aflorar uma série de movimentos (FOUCAULT, 2010b), cada um segundo o seu próprio argumento estimulado por alguns dinamismos obscuros, temas e ideias, conceitos e conhecimentos que devido à sua proximidade ainda não entendemos muito. Trata-se de um volume complexo em que acontecimentos distintos atravessam-se e desenrolam-se segundo regras próprias com práticas que não se podem sobrepor. Ao invés de um grande alinhamento de palavras que traduzem, em caracteres visíveis, pensamentos constituídos, temos, "na densidade dessas práticas discursivas", sistemas que instauram enunciados sobre esse nosso tempo. Faz-se necessário abri-los e tomá-los pelo seu meio para que possamos entendê-los como acontecimentos singulares de agora e tratá-los na densidade que Ihes é peculiar.

Os objetos de nosso tempo podem vir a ganhar densidade na medida em que os tratamos como objetos históricos (FISCHER, 2012), a partir de suas descontinuidades e permanências e naquilo que nos oferecem como ruptura. Parafraseando Fischer (2012, p. 80 ), há um gesto que precisa ser feito, o de interrogar-se sobre as formas de experiência historicamente singular que nos atravessam. É uma opção "não pela história das ideias e mentalidades, mas por descrever, de um lado, as problematizações através das quais nós temos sido constituídos como possibilidade e até necessidade de sermos pensados. $E$, de outro, descrever as próprias práticas no seu interior, em como constituíram-se e constituem-se, tomaram e tomam corpo (FOUCAULT, 1994). Ao descrever os nossos objetos alinhados ao pensamento foucaultiano, não podemos entendê-los como óbvios. Com Foucault, aprendemos que um objeto é uma prática que foi "objetivada" de certa forma, em certo momento e em certo lugar. São as práticas que objetivam um grupo, uma população, um determinado tipo de produção. A partir desse horizonte a descrição de um objeto consiste sobretudo em "expô-lo em suas condições mais amplas de emergência, situando-o em relação a outros conjuntos ou objetos similares" (FISCHER, 2002, p. 65).

A resposta à pergunta inicial do texto - O que resta após um massacre ou o que sobra após a mais miserável das formas de experiência quando se é um professor formador de professores? - é incapaz de ser respondida com formas de pensamento racionalizadas e que terminam em si mesmas, trazendo respostas cheias de certezas. Há uma intensidade nela, pensar a formação de docentes hoje. "Talvez haja na palavra um parentesco essencial entre a morte, a continuidade ilimitada e a representação da linguagem para ela mesma" (FOUCAULT, 2009, p. 48). 
No recuo que o pensamento do filósofo me permite, não encontro uma verdade, tão pouco argumentos que me possibilitem responder a exigência feita por Adorno. Mas, encontro diante de todas essas situações, um complexo feixe de relações que tem permitido trabalhar com as rupturas do presente e com os seus desvios, para analisar de outras perspectivas o que é visível e enunciável sobre esse nosso tempo. Ao interrogar a formação de docentes para provocar encontros, reencontrar conexões, bloqueios e jogos de forças que nos possibilitem percorrer pela contramão do que já nos é conhecido no campo da educação, tão pautado em justificações racionais e interessado em modelos de eficiência.

Assim é possível afirmar que formar professores está mais para um gesto de produção de uma subjetividade docente, uma ética de si docente, um jeito de estar no mundo, do que propriamente a construção de uma dita identidade ou a formação de um perfil profissional que atenda determinadas exigências. "Repensar a formação de professores passa, a meu ver, necessariamente, por considerar a condição humana em sua processualidade, isto é, como sujeitos subjetivados no interior de práticas coletivas, institucionais e sociais" (PEREIRA, 2016, p. 48) - são humanos, trabalhando com a formação de outros humanos, que, por sua vez, trabalharão com a formação geral de outros humanos.

Talvez, ainda seja preciso inverter nossas posições sobre tudo isso que se passa nesse momento, para que sejamos capazes de produzir rupturas e criar outras dinâmicas para os processos formativos nos cursos de Licenciatura. Um professor é alguém que torna inoperante a produtividade do comum e com isso faz com que o assunto, a tarefa e ele próprio se tornem disponíveis. No entanto, essa não é uma competência, uma habilidade, ou um conhecimento que se adquire, antes é uma maneira de vida que se assume. Não como um chamado ou um dom, não como uma essência, mas, como uma forma de existência. Uma atividade desprovida de uma "identidade" que o representa, "em última instância seria uma intensidade" (ORTEGA,1999, p. 62) que aponta para um processo de constituição que substitui seu status de sujeito pela "plenitude da relação consigo". São coisas diferentes que aqui tentamos fazer conversar entre si para que seja possível de algum modo transformar as nossas relações com a atualidade, abrir um espaço experiencial novo, modificar as nossas relações com o campo da educação e entrar em um novo espaço. Trata-se de perscrutar um caminho que "incide, precisamente, sobre si mesmo" (FOUCAULT, 2011, p. 408), não de um reconhecimento de si ou de uma realidade substancial, mas, de exprimir nossas preocupações com o que se passa neste instante.

Na medida em que assumimos a formação como uma micropolítica da subjetividade, ao invés de ensinar, de aprender, de perseguir uma dita articulação entre teoria e prática 
seria preciso mobilizar nossos esforços para pensar no encontro, no cuidado e naquilo que nos une. Inspirado em Terezinha Rios, poderíamos afirmar que formar professores seria trabalhar no horizonte de uma vida partilhada, entre quem está e aqueles que vão chegar - muitas vezes com as ideias daqueles que já habitaram o mundo; uma relação de amor com o mundo como dizem Jan Masschelein e Maarten Simons; uma relação de cuidado consigo e com o outro, como diz Michel Foucault para "colocar em crise os processos de subjetividade aos quais estamos submetidos, com suas formas prontas e estereotipadas" (GRUPO CONTRAFILÉ, 2017, p. 117). ${ }^{11}$

Ao aceitarmos correr o risco e deixar envolver-se com os perigos que nos rondam, estamos de alguma forma também assumindo "paralelamente à produção ética de si, a necessidade de uma pesquisa através das coisas do mundo" (FIAMINI,2004, p. 118). Ao tomar os problemas de nosso tempo pelo meio, não significa apresentar alternativas ou soluções a partir de um modelo. Mas aceitá-los como uma possibilidade de transpor os limites do já conhecido, a fim de criar desvios, inventar outros caminhos e encontrar diferentes possibilidades para redesenhar os nossos objetos de estudo e pesquisa. Não passamos à margem dos problemas e dos enfrentamos que são contemporâneos às nossas investigações, estamos imersos nos problemas e nas possibilidades, falamos e inquietamonos a partir deles. Problematizar o presente não nos permite aceitar uma suposta neutralidade dos nossos gestos, de nossas posições políticas como estudantes, professores e pesquisadores, o que está em jogo "é determinar quais são, em seus mecanismos, em seus efeitos e em suas relações, esses diferentes dispositivos de poder que se exercem, em níveis diferentes da sociedade, em campos e com extensões variadas" (FOUCAULT, 2010, p. 13).

As mudanças sinalizadas no limite dos perigos do nosso tempo, não são apenas no âmbito da educação, mas, em todas as estruturas sociais, desde os processos industriais, com o surgimento cada vez mais rápido de novas tecnologias, e o interesse científico, até a reconfiguração das políticas mundiais com as imigrações. São modificações que vão distanciando-nos de algumas experiências da modernidade que configuraram o campo da educação, alinhando-o a um projeto que visava construir um mundo que almejava "a ordem e a vida civilizada" (VEIGA-NETO, 2007, p. 98).

$\mathrm{Na}$ interrupção desses elos, os contornos do presente vão sendo redesenhados de maneira a "dissolver os pontos em que a vida se encontra asfixiada" (ROLNIK, 2016) e geram "atos de subjetivação" (RANCIÈRE, 2012, p. 63) que demandam mudanças na formação

\footnotetext{
${ }^{11}$ Para conhecer os outros autores ver nas referências Rios (2017) e Masschelein e Simons (2014).
} 
docente, pois redefine-se nela o que é visível, o que se pode dizer e o que os sujeitos são capazes de fazer em relação à escola. Para isso, é necessário colocar em suspeição as operações realizadas com a política do saber nos cursos de licenciatura. Tal gesto seria uma tentativa de provocar um giro na maneira como pensamos a formação docente, não mais restritos a métodos, técnicas, estruturas e regimentos, mas, como uma questão mais ampla, a de defender o estatuto público do saber a fim de fazer das instituições de ensino -sejam elas as escolas ou as universidades-, espaços de possibilidade de encontro com outros mundos, lugares para forjar novas formas de vida. A tarefa que temos diante disso tudo, é a de assumir uma atitude em relação ao tempo de agora e insistentemente retomar a pergunta foucaultiana: o que se passa nesse instante em que somos uns e outros? Sem, no entanto, pensar de acordo com a tradição de um modo de pensar que busca a representação, ou que entoa promessas, mas, de ampliar essas relações afim de problematizar o instante em que vivemos.

\section{REFERÊNCIAS}

ADORNO, T. A educação após Auschwitz (1995). Disponível em: http://adorno.planetaclix.pt/tadorno10.htm. Acesso em: 20 agos. 2018.

AGAMBÉM, G. O que resta de Auschwitz: o arquivo e a testemunha. São Paulo: Boitempo, 2008.

. O que é o contemporâneo? In:

O que é o contemporâneo? e outros ensaios. Chapecó (SC): Argos, 2010. p. 55-73.

AQUINO, J.G. O pensamento como desordem: repercussões do legado foucaultiano. Proposições, São Paulo, v. 25, n. 2 (74), p. 83-102, 2014.

ARTIÈRES, P. Dizer a atualidade. O trabalho de diagnóstico em Michel Foucault. In: GROS, F. (Org.). Foucault: a coragem da verdade. São Paulo: Parábola, 2004. p. 15-37.

BENJAMIN, W. Experiência e pobreza. In: Magia e Técnica, Arte e Política. [Obras Escolhidas]. Trad. Sergio Paulo Rouanet. São Paulo: Brasiliense, 1993. p. 114-119.

FIAMINI, M. O verdadeiro amor e o cuidado comum do mundo. In: GROS, F. Foucault: a coragem da verdade. São Paulo: Parábola Editorial, 2004. p.89-128.

FISCHER, R.M.B. Trabalhar com Foucault: arqueologia de uma paixão. Belo Horizonte: Autêntica, 2012.

Revista Digital do LAV - Santa Maria - vol. 11, n. 3, p. $67-81$ - set./dez. 2018 ISSN 1983 - 7348 http://dx.doi.org/10.5902/1983734832832839 
. Verdades em suspenso: Foucault e os perigos a enfrentar. In: COSTA, M. V. (org.).

Caminhos Investigativos II: outros modos de pensar e fazer pesquisa em educação. Rio de Janeiro: DP\&A, 2002.

FOUCAULT, M. História da Sexualidade II; o uso dos prazeres. Rio de Janeiro: Graal, 1994.

O que são as luzes? In: Ditos \& Escritos, volume II: Arqueologia das ciências e história dos sistemas de pensamento. Rio de Janeiro: Forense Universitária, 2005. p. 335351.

Ditos \& Escritos, volume III: Estética: literatura e pintura, música e cinema. Rio de Janeiro: Forense, 2009.

A ordem do discurso: aula inaugural no Collége de France, pronunciada em 2 de dezembro de 1970. 20. ed. São Paulo: Loyola, 2010.

FOUCAULT, M. Arqueologia do saber. 7. ed. Rio de Janeiro: Forense Universitária, 2010b.

. Em defesa da sociedade: curso no Collége de France. 2. ed. São Paulo: Martins Fontes, 2010c.

Hermenêutica do sujeito. 3. ed. São Paulo: Martins Fontes, 2011.

FRIGOTTO, G. A formação e a profissionalização do educador: novos desafios. In: SILVA, T.T. da; GENTILI, P. Escola S.A.: quem ganha e quem perde no mercado educacional do neoliberalismo. Brasília: CNTE, 1996. p. 75-105.

GRUPO CONTRAFILÉ. Onde o comum se faz possível. In: SIMPÓSIO INTERNACIONAL FORMAÇÃO DE EDUCADORES EM ARTE E PEDAGOGIA, 3, 2017, São Paulo, SP. Anais [...] São Paulo: MACKENZIE, 2017. p.115-118.

MASSCHELEIN, J.; SIMONS, M. Em defesa da escola: uma questão pública. Belo Horizonte: Autêntica, 2014.

ORTEGA, F. Amizade e estética da existência em Foucault. Rio de Janeiro: Graal, 1999.

Revista Digital do LAV - Santa Maria - vol. 11, n. 3, p. $67-81$ - set./dez. 2018 ISSN $1983-7348$ http://dx.doi.org/10.5902/1983734832832839 
PELBART, P.P. Excurso sobre o desastre. (2011) Disponível em: https://revistapolichinelo.blogspot.com.br/2011/07/excurso-sobre-o-desastre.html. Acesso em: 29 set. 2018.

PereirA, M. V. Estética da Professoralidade: um estudo crítico sobre a formação do professor. Santa Maria: Editora da UFSM, 2016.

RANCIÈRE, J. O espectador emancipado. São Paulo: Martins Fontes, 2012.

RIOS, T.A. O desafio da convivência colaborativa. In: SIMPÓSIO INTERNACIONAL FORMAÇÃO DE EDUCADORES EM ARTE E PEDAGOGIA, 3, 2017, São Paulo, SP. Anais [...]. São Paulo: MACKENZIE, 2017. p.119-127.

ROLNIK, S. A hora da micropolítica (2016). Disponível em https://laboratoriodesensibilidades.wordpress.com/2016/06/07/suely-rolnik-a-hora-damicropolitica/. Acesso em: 30 jul., 2018.

VEIGA-NETO, A. Pensar a escola como instituição que pelo menos garanta a manutenção das conquistas fundamentais da modernidade. In: COSTA, M.V. A escola tem futuro? 2.ed. Rio de Janeiro: Lamparina, 2007. p.96-118.

\footnotetext{
' Mestre e Doutorando em Educação pela Universidade Federal do Rio Grande do Sul UFRGS. Especialista em Educação Interdisciplinar pelo Instituto de Desenvolvimento do Alto Uruguai - IDEAU. Graduado em Licenciatura em Artes pela Universidade do Oeste de Santa Catarina. É Professor das áreas de teorias e ensino das artes na Universidade do Alto Vale do Rio do Peixe - UNIARP em Caçador e da Faculdade SENAC. É membro dos Grupos de Pesquisa Arte na Pedagogia-GPAP (Mackenzie); ARTEVERSA-Grupo de estudo e pesquisa em arte e docência (UFRGS). Além de atuar como pesquisador voluntário do Grupo Pensu: estudo e pesquisa sobre ensino superior.
}

Como citar esse artigo:

MOMOLI, Daniel Bruno. Formar professores, um gesto de resistência. Revista Digital do LAV, Santa Maria: UFSM, v. 11, n. 3, p. $67-81$, set./dez. 2018. 